\title{
Significance of the Single Umbilical Artery
}

\section{A Clinical, Radiological, Chromosomal, and Dermatoglyphic Study}

\author{
R. F. VLIETINCK, M. THIERY, E. ORYE, A. DE CLERCQ, and P. VAN VAERENBERGH \\ From the Paediatric Clinic and the Department of Obstetrics of the State University of Ghent, Belgium
}

\begin{abstract}
Vlietinck, R. F., Thiery, M., Orye, E., de Clercq, A., and van Vaerenbergh, P. (1972). Archives of Disease in Childhood, 47, 639. Significance of the single umbilical artery: a clinical, radiological, chromosomal, and dermatoglyphic study. A single umbilical artery is present in about $1 \%$ of all singletons. It is associated with a wide range of congenital malformations. Chromosomal analysis of our surviving cases gave normal results. Dermatoglyphic patterns were normal, except that the boys showed a three- to fourfold increase in the number of the radial loops on the fingers, and a lowering of the total finger ridge count. Evidence favouring a common non-genetic cause for both a single umbilical artery and the associated malformations is discussed.
\end{abstract}

Although the absence of one umbilical artery was first reported a century ago (Hyrtl, 1870), the significance of a single umbilical artery (SUA) has only been realized since a retrospective study by Benirschke and Brown (1955) showed it was associated with increased incidence of congenital anomalies. Because most of the investigations on SUA have been made by pathologists, the conclusions drawn may not be applicable to the live infant population. And because most of these studies are retrospective, they may also be biased with respect to the incidence of congenital malformations.

The present report concerns a prospective study carried out in a consecutive series of 2572 singletons born in the same hospital and followed up over a period of several years by means of a planned investigative programme including intravenous pyelography (IVP), chromosome patterns, and dermatoglyphs.

\section{Methods}

In this investigation the umbilical cord was studied in various ways: gross examination of the freshly delivered umbilical cord and placenta; re-examination after fixation for one week in $10 \%$ formaldehyde, followed by the study of $\mathrm{H}$. and E.-stained paraffin sections prepared from the middle portion of the cord.

All children with SUA who succumbed during the perinatal period were necropsied. Follow-up study of the survivors included clinical examination, IVP, and

Received 13 December 1971. investigation of the karyotype and dermatoglyphs. The mean age at the last examination was 21 months (range, 5 months to $3 \frac{1}{2}$ years).

\section{Results}

Incidence and mortality. In 29 of the 2572 consecutive cords examined ( $1 \cdot 1 \%)$, one umbilical artery was lacking. The significance of SUA, and its association with such factors as birthweight, maternal pathology, and placental pathology have been discussed elsewhere (de Clercq et al., 1970).

Of the 29 children with SUA, 4 were stillborn and 2 died neonatally, giving a perinatal mortality rate of $21 \%$. Half of the stillborn fetuses $(2 / 29$ : $7 \%$ ) showed congenital malformations (Table I).

Of the 23 children with SUA still living, 22 were given a complete clinical and neurological examination. In one case examination was refused by the parents; this child had been found to be grossly normal at birth and showed no malformations at the age of 32 months. Only the 22 children that were fully followed up will be discussed here.

Five patients had a height that was more than 2 SDs below the mean, and two exceeded the mean. Consequently, the histogram for length shows a pronounced negative skewness, though for the whole group no statistically significant difference from the normal population was found. The distribution for weight and head circumference was Gaussian, and the values for both were in accordance with those of the normal population. 
TABLE I

Congenital Malformations with Single Umbilical Artery, Present Series

\begin{tabular}{|c|c|c|c|}
\hline Grade & Frequency & Type & Outcome \\
\hline Major (14\%) & $\begin{array}{l}2 / 29=7 \% \quad\left\{\begin{array}{l}1 \\
1\end{array}\right. \\
2 / 22=9 \% \quad\left\{\begin{array}{l}1 \\
1\end{array}\right. \\
1 / 19=5 \% \\
4 / 22=18 \% \quad 4\end{array}$ & $\begin{array}{l}\text { Internal hydrocephaly } \\
\text { Coarctation of aorta and polycystic kidneys } \\
\text { Supravalvular aortic stenosis } \\
\text { Talipes } \\
\text { Renal pelvis duplicated } \\
\text { Tuberous haemangioma }\end{array}$ & $\begin{array}{l}\text { Stillborn } \\
\text { Living }\end{array}$ \\
\hline Total & 9 & & \\
\hline
\end{tabular}

Psychomotor development was evaluated. All the children except one with a post-meningitis hydrocephalus passed their milestones at the normal age.

At physical examination, two children $(2 / 22=$ $9 \%$ ) had disabling malformations (Table I): one boy showed a supravalvular aortic stenosis, not associated with idiopathic hypercalcaemia, the other, also a boy, had congenital clubfeet at birth; this child contracted bacterial meningitis during his first month, became hydrocephalic, and showed mental retardation. Four children $(4 / 22=18 \%)$ had superficial angiomatous naevi ('strawberry naevi') measuring more than $3 \times 1 \mathrm{~cm}$. In two of them the lesions were multiple, bilateral, and distributed over the chest, abdomen, and hands (Table I).

Radiology. Of the 22 living children, an IVP was undertaken in 19; all but one had a normal configuration of the kidneys and urine collecting system. This patient $(1 / 19: 5 \%)$ had complete duplication of the left renal pelvis (Table I).

In half of the patients accurate measurement of the renal size could be made, and this was normal, with a mean 0.5 standard error below the mean of controls.

Thus, the overall incidence of diagnosed major congenital malformations amount to $4 / 29$ or $14 \%$.

Karyotype and dermatoglyphs. Blood lymphocytes were successfully cultured in 19 cases. For each patient, 20 well-spread mitoses were counted and 5 were karyotyped. All these patients displayed 46 normal chromosomes, with no structural anomalies or excessive breaks or recombinations.*

In 18 children (10 boys, 8 girls) the dermatoglyphs were analysed. The fingerprints of children born with SUA differ significantly from those found in the normal population. In male patients

\footnotetext{
* Since the completion of this study, two further patients were investigated with the same results.
}

with SUA the total finger ridge count had a mean of 91.5 as compared with 145 for the normal controls $(P<0 \cdot 05)$. All but two of the boys had total counts below 100, because SUA males show less than half the normal frequency of whorls. The frequency of radial loops was three times normal. In the girls, the total finger ridge count was higher $(156 \cdot 5)$ than in normal controls (125), but this difference is not statistically significant. Only one girl had a value below 140 . None of the girls had any arch, a pattern normally occurring more frequently in girls than in boys. Females with SUA had a fourfold frequency of radial loops as compared to normal controls. The palm prints showed normal flexion creases; none of the patients had either simian or Sidney lines. The maximal atd-angle was normal, as was the $\mathrm{AD}$-index. The digital triradii and main lines were all present and showed a normal course. The interdigital, hypothenar, and thenar areas did not show any unusual pattern.

\section{Discussion}

As can be seen from Table $I$, the total incidence of congenital malformations differs significantly from that of the normal population. The wide ranges found in the literature are probably attributable to at least two biases. Because one group of authors obtained their material from a department of pathology, selection must have increased the incidence of malformations reported. Prospective studies generally yield correct incidences for the various malformations diagnosed at birth. But because an important fraction of the anomalies only become manifest later in life, a more exhaustive examination, including radiological methods, increases the incidence. A systematic investigation of the urinary tract by IVP was performed by Feingold, Fine, and Ingall (1964), who found 8/24 (33\%) abnormal urograms. VanLeeuwen, Behringer, and Glenn (1967) obtained a normal IVP 
in all of the 6 children examined, and Schroyer (1967) found only 3 minor deviations from the normal in 26 urograms. In our study we have combined cord examination with long-term followup (up to 3.5 years) and with specialized examinations of all the children with SUA born in one hospital during a period of time.

On the basis of data in the literature (Fig. 1A, Tables II and III), and without taking into account the fetal wastage due to spontaneous abortions

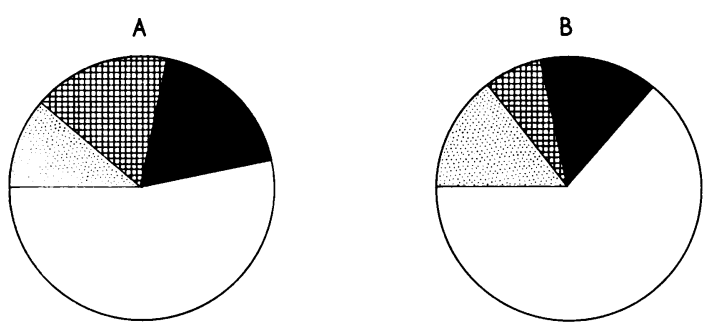

Stillborn
Cirst year
Congenital malformation

FIG.-Frequency of mortality and of congenital malformations in single umbilical artery. $A$, data reported in the literature; $B$, present series. with SUA $(2 \cdot 4 \%$ according to Javert, 1957, and Thomas, 1963), it can be shown that of 100 fetuses with SUA reaching term, 11 are born dead and another 17 die within the first year; thus, only $72 \%$ remain alive. Of the latter, one-fourth $(18 \%)$ are malformed, which leaves a figure of $54 \%$ healthy children. Freely quoting Faierman (1960): of every three children in whom SUA is diagnosed but who show no obvious malformation at birth, one harbours a lethal but unrecognized anomaly, and one has a malformation correctable surgically; only one out of three is normal. According to our own results (Fig. 1B), $21 \%$ of the children die (stillborn $14 \%$, death in first year $7 \%$ ) and $14 \%$ have congenital malformations, sufficiently severe to cause disability.

Most authors agree that concomitant congenital anomalies lack organ specificity. The sireniform monster and the acardiacus, the most severe manifestations of this syndrome, are invariably associated with SUA (Schatz, 1898-1900; Ballantyne, 1904; Kampmeier, 1927; Hendry and Kohler, 1956; Slípka and Kočová, 1970), while heart disease, urogenital abnormalities, and skeletal malformations are common. Though of minor importance, tuberous haemangioma has shown a surprisingly high incidence in our SUA group, an association not previously reported.

TABLE II

Congenital Malformations with Single Umbilical Artery, Reported in Literature ${ }^{\star}$

\begin{tabular}{|c|c|c|c|c|c|c|c|c|c|}
\hline \multicolumn{7}{|c|}{ Type of Study } & \multirow{2}{*}{\multicolumn{3}{|c|}{ All SUA Studies }} \\
\hline & \multicolumn{3}{|c|}{ Prospective } & \multicolumn{3}{|c|}{ Retrospective } & & & \\
\hline & Total & No. of Cases & $\%$ & Total & No of Cases & $\%$ & Total & No. of Cases & $\%$ \\
\hline $\begin{array}{l}\text { Living } \\
\text { Dead }\end{array}$ & $\begin{array}{r}396 \\
89\end{array}$ & $\begin{array}{r}100 \\
48\end{array}$ & $\begin{array}{l}25 \cdot 0 \\
54 \cdot 0\end{array}$ & $\begin{array}{l}(28) \\
141\end{array}$ & $\begin{array}{l}(2) \\
75\end{array}$ & $\begin{array}{l}(7 \cdot 1) \\
53 \cdot 0\end{array}$ & $\begin{array}{l}483 \\
250\end{array}$ & $\begin{array}{l}121 \\
123\end{array}$ & $\begin{array}{l}25 \cdot 0 \\
49 \cdot 5\end{array}$ \\
\hline
\end{tabular}

^A complete reference list can be obtained from one of the authors (R.F.V.).

TABLE III

Mortality in Single Umbilical Artery, as Reported in Literature ${ }^{\star}$

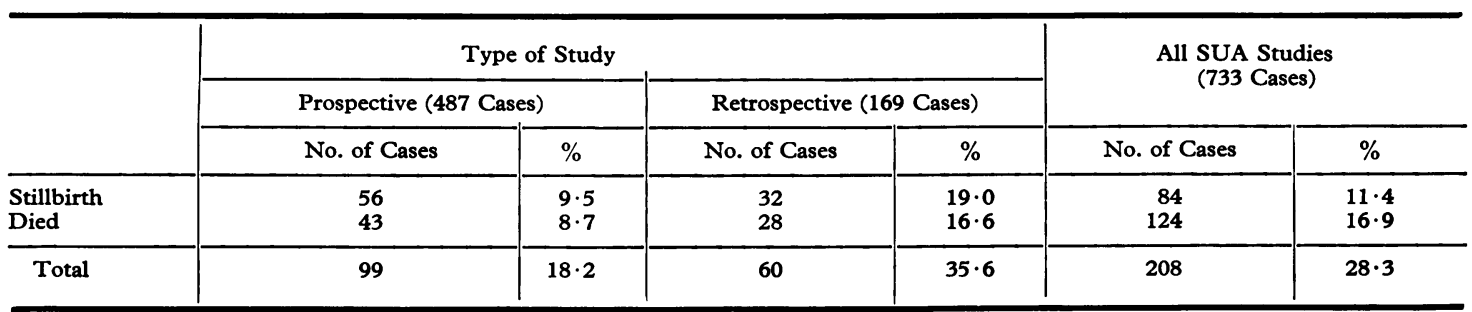

^A complete reference list can be obtained from one of the authors (R.F.V.). 
Little is known about the aetiology of the SUA syndrome. A chromosomal aetiology has been suggested on the basis of (1) the high fetal wastage (Javert, 1957; Bourne and Benirschke, 1960; Thomas, 1963); (2) the wide variety of severe congenital malformations; and (3) the reported association of SUA with trisomy (especially trisomy-18 and -13 , but also mongolism) and with gonadal dysgenesis (Richart and Benirschke, 1958; German et al., 1962; Uchida, Bowman, and Wang, 1962; Lewis, 1962; Feingold et al., 1964; Gustavson, 1964; Gustavson et al., 1964; Seki and Strauss, 1964; VanLeeuwen et al., 1967; Dellenbach et al., 1968). As a result of our series of patients where chromosomes and dermatoglyphs were studied, we are led to conclude that SUA is no more than a fortuitous organ manifestation of trisomy.

Only two instances of familial SUA syndrome (Adler, Lewenthal, and Ben-Adereth, 1963; Dellenbach et al., 1968) are on record. Of the twins studied, all but three cases (Fasolis and Okely, 1961; Fujikura, 1964; Slípka and Kočová, 1970) were found to be discordant irrespective of their zygosity. Numerous authors have found no consanguinity among the SUA families (Bourne and Benirschke, 1960), as has been our own experience. The association of SUA with thalidomide embryopathy (Russell and McKichan, 1962; Dunn, Fisher, and Kohler, 1962; Thomas, 1963; Kajii et al., 1963) and the prevalence of children with SUA born to women in whom ovulation has been induced (Hack et al., 1970) argues for a teratogenic aetiology of the syndrome. The wide variety of affected organs indicates that there is no critical embryonic stage (Benirschke and Brown, 1955; Faierman, 1960; Bourne and Benirschke, 1960), and that the factor(s) must be capable of acting very early and probably over a long period of time. The disturbances of organogenesis by chromosomal aberrations and by chemical agents exemplify this.

\section{REFERENCES}

Adler, J., Lewenthal, H., and Ben-Adereth, N. (1963). Absence of one umbilical artery and its relationship to congenital malformations. (Hebrew.) Harefuah, 65, 286.

Ballantyne, J. W. (1904). Manual of Antenatal Pathology and Hygiene: The Embryo, Vol. II, p. 592. W. Green, Edinburgh.

Benirschke, K., and Brown, W. H. (1955). A vascular anomaly of the umbilical cord: the absence of one umbilical artery in the umbilical cords of normal and abnormal fetuses. Obstetrics and Gynecology, 6, 399.

Bourne, G. L., and Benirschke, K. (1960). Absent umbilical artery. Archives of Disease in Childhood, 35, 534.

de Clercq, A., Vlietinck, R. F., van Vaerenbergh, P., Thiery, M., and Derom, R. (1970). Agenesie van een arteria umbilicalis. Tijdschrift voor Geneeskunde, 26, 1051.
Dellenbach, P., Leissner, P., Philippe, E., Gillet, J. Y., and Muller, P. (1968). Artère ombilicale unique, insertion vélamenteuse du cordon ombilical et malformations foetales. Revue Française de Gynécologie et d'Obstétrique, 63, 603.

Dunn, P. M., Fisher, A. M., and Kohler, H. G. (1962). Phocomelia. American fournal of Obstetrics and Gynecology, 84, 348.

Faierman, E. (1960). The significance of one umbilical artery. Archives of Disease in Childhood, 35, 285.

Fasolis, S., and Okely, S. (1961). Agenesia dell'arteria ombelicale destra in entrambi gli individui di coppia gemellare. Folia Hereditaria et Pathologica, 10, 115.

Feingold, M., Fine, R. N., and Ingall, D. (1964). Intravenous pyelography in infants with single umbilical artery. New England fournal of Medicine, 270, 1178.

Fujikura, T. (1964). Single umbilical artery and congenital malformations. American fournal of Obstetrics and Gynecology, $88,829$.

German, J. L., Rankin, J. K., Harrison, P. A., Donovan, D. J., Hogan, W. J., and Bearn, A. G. (1962). Autosomal trisomy of a group 16-18 chromosome. Fournal of Pediatrics, 60, 503

Gustavson, K. H. (1964). Down's Syndrome, pp. 88 and 95. Almqvist and Wiksell, for University of Uppsala Institute for Medical Genetics, Uppsala.

Gustavson, K. H., Finley, S. C., Finley, W. H., and Jalling, B. (1964). A 4-5/21-22 chromosomal translocation associated with multiple congenital anomalies. Acta Paediatrica, 53, 172.

Hack, M., Brish, M., Serr, D. M., Insler, V., and Lunenfeld, B. (1970). Outcome of pregnancy after induced ovulation. fournal of the American Medical Association, 211, 791.

Hendry, D. W., and Kohler, H. G. (1956). Sirenomelia. Fournal of Obstetrics and Gynaecology of the British Empire, 63, 865.

Hyrtl, J. (1870). Die Blutgefässe der menschlichen Nachgeburt in normalen und abnormen Verhältnissen. W. Braumüller, Vienna.

Javert, C. T. (1957). Spontaneous and Habitual Abortion. Blakiston, New York.

Kajii, T., Shinohara, M., Kikuchi, K., Dohmen, S., and Akichika, M. (1963). Thalidomide and the umbilical artery. (Letter.) Lancet, 2, 889.

Kampmeier, O. F. (1927). On sireniform monsters, with a consideration of the causation and the predominance of the male sex among them. Anatomical Record, 34-35, 365.

Lewis, A. J. (1962). Autosomal trisomy. (Letter.) Lancet, 1, 866. Richart, R., and Benirschke, K. (1958). Gonadal dysgenesis in a newborn infant. New England fournal of Medicine, 258, 974.

Russell, C. S., and McKichan, M. D. (1962). Thalidomide and congenital anomalies. (Letter.) Lancet, 1, 429.

Schatz, F. (1898-1900). Die Gefässverbindungen der Placentakreisläufe eineiiger Zwillinge, ihre Entwicklung und ihre Folge. Archiv für Gynäkologie, 55, 485; 58, 1; 60, 81, $201,559$.

Schroyer, W. W. (1967). Single umbilical artery. A research for associated renal agenesis. Personal communication to Benirschke. In The Pathology of the Human Placenta. By $\mathrm{K}$. Benirschke and S. G. Driscoll. Springer, New York and Berlin. Seki, M., and Strauss, L. (1964). Absence of one umbilical artery: analysis of 60 cases with emphasis on associated developmental aberrations. Archives of Pathology, 78, 446.

Slipka, J., and Kočová, J. (1970). The absence of one umbilical artery in malformed MZ twins. Acta Geneticae Medicae et Gemellologiae, 19, 567.

Thomas, J. (1963). Die Entwicklung von Fetus und Plazenta bei Nabelgefässanomalien. Archiv für Gynäkologie, 198, 216.

Uchida, I. A., Bowman, J. M., and Wang, H. C. (1962). The 18trisomy syndrome. New England fournal of Medicine, 266, 1198.

VanLeeuwen, G., Behringer, B., and Glenn, L. (1967). Single umbilical artery. Fournal of Pediatrics, 71, 103.

Correspondence to Professor M. Thiery, Verloskundige Klinick, Academisch Zickenhuis, De Pintelaan 135, 9000 Ghent, Belgium 